\title{
Ester Transfer Reaction of Aromatic Esters with Haloarenes and Arenols by a Nickel Catalyst
}

\author{
Ryota Isshiki, Naomi Inayama, Kei Muto, and Junichiro Yamaguchi* \\ Department of Applied Chemistry, Waseda University, 3-4-1 Ohkubo, Shinjuku, Tokyo 169-8555, Japan. \\ Supporting Information Placeholder
}

\begin{abstract}
A catalytic ester transfer reaction of aromatic esters with aryl halides/arenols was developed. The present reaction can transfer an ester functional group from certain aromatic esters to haloarenes. This ester transfer reaction involves two oxidative additions - one from the $\mathrm{C}-\mathrm{C}$ bond of the aromatic ester and one from the $\mathrm{C}$-halogen bond of haloarenes - onto a nickel catalyst. The utilization of a $\mathrm{Ni}$ /dcypt catalyst capable of cleaving both chemical bonds was a key for the reaction progress. Furthermore, naphtholbased aryl electrophiles were also applicable to the catalytic system via $\mathrm{C}-\mathrm{O}$ bond activation.
\end{abstract}

Development of novel substitution reactions of aromatic cores is a continually important topic in organic synthesis. Classically, $\mathrm{C}-\mathrm{N}$ or $\mathrm{C}-\mathrm{Br}$ bonds on arenes have been constructed by an electrophilic aromatic substitution. Cross-coupling-based strategies such as Buchwald-Hartwig amination and Ullmann condensation have also been utilized for this purpose. ${ }^{[1]}$ For the synthesis of arenecarboxylic acids and related esters, the carbonylative reactions using $\mathrm{CO}$ have found wide use (Figure 1A). ${ }^{[2]}$ However, this gaseous manipulation is preferably avoided, owing to its cumbersome reaction setup and toxicity. Several alternative methods using safety $\mathrm{CO}$ surrogates have been developed to synthesize aromatic esters while avoiding the handling of $\mathrm{CO}$ gas. ${ }^{[3]}$

Meanwhile, functional group metathesis reactions have been emerging as a conceptually distinct synthetic strategy. ${ }^{[4]}$ In 2018, Morandi and Arndtsen independently reported a functional group metathesis of aroyl chlorides and aryl iodides catalyzed by a Pd-Xantphos complex (Figure 1B). ${ }^{[5]}$ These methods used an oxidative addition and a reductive elimination of two distinct chemical bonds $(\mathrm{C}-\mathrm{I}$ and $\mathrm{C}-\mathrm{Cl}$ ) as a reversible chemical process. Enlightened by these reports, we turned our attention to use aromatic esters instead of moisture-sensitive aroyl chlorides. Our campaign to study the decarbonylative transformation of aromatic esters revealed that the use of Ni- or Pd-dcypt (dcypt: 3,4-bis(dicyclohexylphosphino)thiophene) catalysts was effective to formally cleave the $\mathrm{C}-\mathrm{C}$ bond of aromatic esters through oxidative additions of the $\mathrm{C}(\mathrm{acyl})-\mathrm{O}$ bond followed by decarbonylation. ${ }^{[6,7]}$ Moreover, the same catalysts can also enable the oxidative addition of aryl halides or arenols. ${ }^{[8]}$ Thus, there is an opportunity to extend the functional group metathesis strategy to the reaction of aromatic esters with aryl halides as well as arenols. Such a reaction would also give aromatic esters as chemically stable products compared with the corresponding aroyl chlorides. We herein report our efforts toward the development of an ester transfer reaction from aromatic esters to haloarenes as well as arenols.

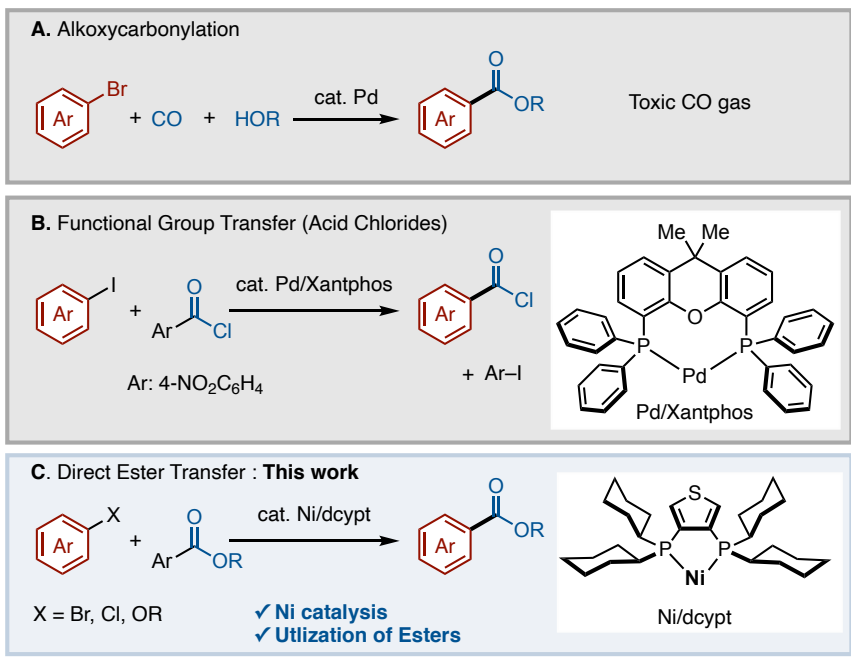

Figure 1. Catalytic synthesis of aromatic carboxylates. (A) Alkoxycarbonylation (B) functional group transfer using acyl chlorides (C) direct ester transfer.

At the outset, we optimized reaction conditions by using 4bromoanisole (1A) and phenyl nicotinate (2a) as model substrates (Table 1). In line with our hypothesis, under the influence of $\mathrm{Ni}(\mathrm{OAc})_{2} /$ dcypt catalyst with $\mathrm{Zn}$ and $\mathrm{Na}_{2} \mathrm{CO}_{3}$, the reaction of $\mathbf{1 A}$ and $\mathbf{2 a}$ gave the ester transferred product $\mathbf{3 A}$ in $42 \%$ yield (Table 1 , entry 1 ). A structurally related thiophenebased ligand dcppt (3,4-bis(dicyclopentylphosphino)thiophene), also produced $\mathbf{3 A}$ in a slightly lower yield (Table 1, entry 2). Interestingly, although dcype (1,2- 
bis(dicyclohexylphosphino)ethane) was known to affect decarbonylative couplings, ${ }^{[6]}$ this was totally ineffective in the present reaction (Table 1, entry 3). Xantphos, which is effective for Morandi's as well as Arndtsen's transfer reaction, ${ }^{[5]} \mathrm{did}$ not lead to the production of $3 \mathrm{~A}$ (Table 1, entry 4). Other typical phosphine ligands such as dppp and $\mathrm{PPh}_{3}$ did not work at all in the present reaction (Table 1, entries 5 and 6). Although NHC-based ligands can affect the decarbonylative reaction of aromatic esters, ${ }^{[6]}$ IPr did not delivered 3A (Table 1, entry 7). Through the screening of ligands, unfortunately, $\mathrm{Ar}-\mathrm{Br} 4$ as a possible co-product was not observed. In this study, we used $\mathrm{Zn}$ powder as a reductant of $\mathrm{Ni}(\mathrm{II})$ to generate the active $\mathrm{Ni}(0)$ species. A similar effect can be expected for $\mathrm{Sn}$ and $\mathrm{Mn}$ powder, however, they decreased the reaction yield (Table 1 , entries 8 and 9). ${ }^{[9]}$ Although the reaction does not seem to require the base, the addition of $\mathrm{Na}_{2} \mathrm{CO}_{3}$ improved the reaction yield (Table 1, entries 1, 10-12). Of note, we did not obtain 3A when palladium catalysis was used instead of nickel (Table 1 , entry 13). Further improvement was achieved by the addition of DMAP, in which $3 \mathrm{~A}$ was generated in $60 \%$ yield (Table 1 , entry 14). Using another pyridine base, 2,6-lutidine also resulted in a slight improvement though but not as much as when using DMAP (Table 1, entry 15). Other nucleophilic nitrogen bases, DBU and DABCO, did not increase the reaction yield (Table 1, entries 16 and 17). Although the role of DMAP is totally unclear at this stage, we consider the two possible roles of DMAP: One is that DMAP could support the oxidative addition of aromatic esters to the nickel catalyst through the generation of a transient aroyl-DMAP species. ${ }^{[10]}$ Another role is that DMAP would work as a co-ligand of nickel. ${ }^{[11]}$ Through the above studies, we identified the optimized conditions as $\mathrm{Ni}(\mathrm{OAc})_{2} / \mathrm{dcypt} / \mathrm{Zn} / \mathrm{Na}_{2} \mathrm{CO}_{3} / \mathrm{DMAP}$ catalysis.

Table 1. Optimization of Reaction Conditions ${ }^{a}$

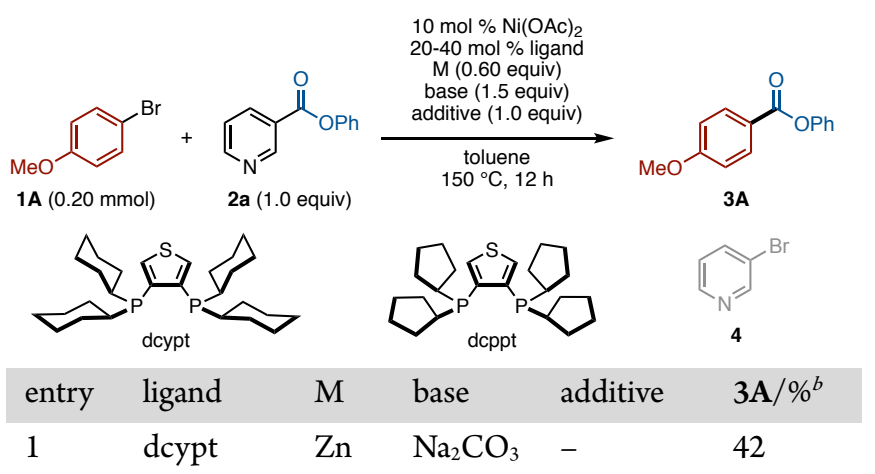

$\begin{array}{llllll}2 & \text { dcppt } & \mathrm{Zn} & \mathrm{Na}_{2} \mathrm{CO}_{3}- & 36 \\ 3 & \text { dcype } & \mathrm{Zn} & \mathrm{Na}_{2} \mathrm{CO}_{3}- & 0 \\ 4 & \text { Xantphos } & \mathrm{Zn} & \mathrm{Na}_{2} \mathrm{CO}_{3}- & 0 \\ 5 & \text { dppp } & \mathrm{Zn} & \mathrm{Na}_{2} \mathrm{CO}_{3}- & 0 \\ 6 & \mathrm{PPh} & \mathrm{Zn} & \mathrm{Na}_{2} \mathrm{CO}_{3} & - & 0 \\ 7^{c} & \mathrm{IPr} \cdot \mathrm{HCl} & \mathrm{Zn} & \mathrm{Na}_{2} \mathrm{CO}_{3} & - & 0 \\ 8 & \text { dcypt } & \mathrm{Sn} & \mathrm{Na}_{2} \mathrm{CO}_{3}- & 17 \\ 9 & \text { dcypt } & \mathrm{Mn} & \mathrm{Na}_{2} \mathrm{CO}_{3}- & 34 \\ 10 & \text { dcypt } & \mathrm{Zn} & \mathrm{CaCO}_{3} & - & 26 \\ 11 & \text { dcypt } & \mathrm{Zn} & \mathrm{NaOAc}^{2}- & 28 \\ 12 & \text { dcypt } & \mathrm{Zn} & \mathrm{none}^{2} & - & 24 \\ 13^{d} & \text { dcypt } & \mathrm{Zn} & \mathrm{Na}_{2} \mathrm{CO}_{3} & - & 0 \\ 14 & \text { dcypt } & \mathrm{Zn} & \mathrm{Na}_{2} \mathrm{CO}_{3} & \text { DMAP } & 60 \\ 15 & \text { dcypt } & \mathrm{Zn} & \mathrm{Na}_{2} \mathrm{CO}_{3} & \text { lutidine } & 45 \\ 16 & \text { dcypt } & \mathrm{Zn} & \mathrm{Na}_{2} \mathrm{CO}_{3} & \text { DBU } & 37 \\ 17 & \text { dcypt } & \mathrm{Zn} & \mathrm{Na}_{2} \mathrm{CO}_{3} & \text { DABCO } & 33\end{array}$

${ }^{a}$ Conditions: 1A (0.20 mmol), 2a $(0.20 \mathrm{mmol}), \mathrm{Ni}(\mathrm{OAc})_{2}$ (10 mol \%), ligand (bidentate, $20 \mathrm{~mol} \%$; monodentate, 40 mol \%), $\mathrm{M}$ ( 0.60 equiv), base ( 1.5 equiv), additive (1.0 equiv), toluene $(0.80 \mathrm{~mL}), 150{ }^{\circ} \mathrm{C}, 12 \mathrm{~h} .{ }^{b} \mathrm{GC}$ yield. ${ }^{c} \mathrm{NaO} t$-Bu $(25$ mol \%) was added. ${ }^{d} \mathrm{Pd}(\mathrm{OAc})_{2}(10 \mathrm{~mol} \%)$ was used instead of $\mathrm{Ni}(\mathrm{OAc})_{2}$.

With the optimized conditions, we next investigated the substrate scope using $\mathbf{2 a}$ as an ester source (Scheme 1). Electron-donating aryl bromides generally reacted to give the corresponding aromatic esters. $m$-Anisyl bromide (1B) reacted less efficiently than $p$-anisyl bromide (1A). Several aryl bromides with alkoxy groups including phenoxy were reacted to give the corresponding aromatic esters in moderate yields (3C-3G). Less electron-rich aryl bromides such as $m$ - or $p$ alkylphenyl bromides also underwent to the present reaction, albeit affording lower yields of products $3 \mathrm{H}-3 \mathrm{~L}$ when compared to the alkoxylated arenes. Unfortunately, at this stage, $o$ substituted aryl bromides showed poor reactivity, affording the corresponding product in less than $20 \%$ yield (see the Supporting Information). Acetal ( $3 \mathbf{M})$ and fluoro $(3 \mathbf{N})$ groups were tolerated under the reaction conditions. Triarylaminebased aromatic ester 3P was successfully synthesized by the present method in $30 \%$ yield. Furthermore, naphthalene ester $3 \mathbf{Q}$ was also produced.

Scheme 1. Substrate Scope ${ }^{a}$ 

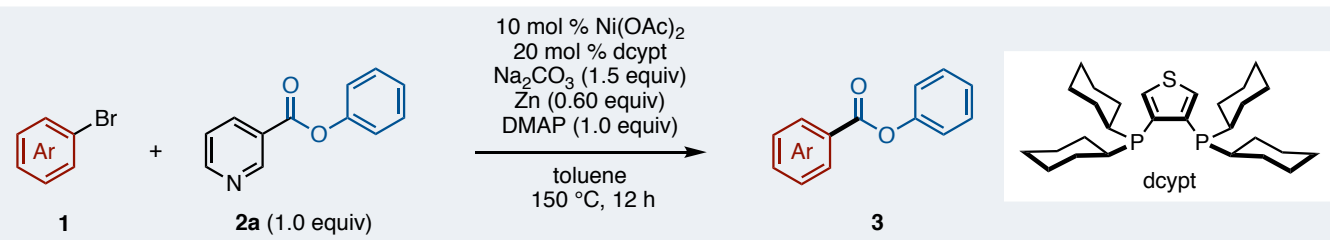

Structure of 3

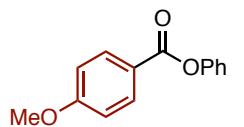

3A: $50 \%(64 \%)$<smiles>O=C(Oc1ccccc1)c1ccc(Oc2ccccc2)cc1</smiles>

3G: $47 \%(50 \%)$<smiles>O=C(O)c1ccc(C2OCCO2)cc1</smiles>

3M: $31 \%(55 \%)$

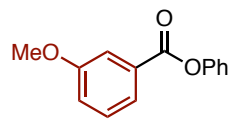

3B: $30 \%(37 \%)$<smiles>Cc1ccc(C(=O)Oc2ccccc2)cc1</smiles>

3H: $34 \%(50 \%)^{b, c}$<smiles>O=C(O)c1ccc(F)cc1</smiles>

3N: $40 \%(50 \%)^{b}$

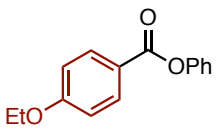

3C: $41 \%(65 \%)$<smiles>Cc1cccc(C(=O)Oc2ccccc2)c1</smiles>

3I: $29 \%(38 \%)^{b}$<smiles>O=C(O)c1ccc(-c2ccccc2)cc1</smiles>

30: $41 \%(56 \%)$<smiles>O=C(Oc1ccccc1)c1ccc(O)cc1</smiles>

3D: $48 \%(61 \%)$<smiles>CCc1ccc(C(=O)Oc2ccccc2)cc1</smiles>

3J: $30 \%(36 \%)^{b, c}$<smiles>O=C(Oc1ccccc1)c1ccc(N(c2ccccc2)c2ccccc2)cc1</smiles>

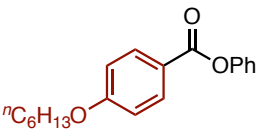

3E: $62 \%(56 \%)$<smiles>CC(C)c1ccc(C(=O)Oc2ccccc2)cc1</smiles>

3K: $22 \%(28 \%)^{b}$<smiles>O=C(c1ccccc1)c1ccc2ccccc2c1</smiles>

3Q: $30 \%(39 \%)$<smiles>O=C(O)c1ccc(Br)cc1</smiles>

3F: $41 \%(66 \%)$<smiles>CC(C)(C)[13CH3]</smiles>

${ }^{a}$ Conditions: $1(0.20 \mathrm{mmol}), 2 \mathrm{a}(0.20 \mathrm{mmol}), \mathrm{Ni}(\mathrm{OAc})_{2}(10 \mathrm{~mol} \%)$, dcypt $(20 \mathrm{~mol} \%)$, Zn powder $(0.60$ equiv $), \mathrm{Na}_{2} \mathrm{CO}_{3}(1.5$ equiv $)$, DMAP ( 1.0 equiv), toluene $(0.80 \mathrm{~mL}), 150^{\circ} \mathrm{C}, 12 \mathrm{~h}$. Numbers in parenthesis show NMR yield. ${ }^{b}$ inseparable mixture with phenyl benzoate. Isolated yields were determined by ${ }^{1} \mathrm{H}$ NMR ratio. ${ }^{c} 170{ }^{\circ} \mathrm{C}, 24 \mathrm{~h}$. ${ }^{d} 2$-Chloronaphthalene (4) was used without DMAP.

A plausible mechanism of this reaction is illustrated in Scheme 2. $\mathrm{Ni}$ /dcypt cleaves the $\mathrm{C}-\mathrm{Br}$ bond of an aryl bromide and the $\mathrm{C}-\mathrm{C}$ bond of phenyl nicotinate (2a) to generate $\mathrm{Ar}-$ $\mathrm{Ni}-\mathrm{Br}$ (B) and $\mathrm{Py}-\mathrm{Ni}(\mathrm{CO})-\mathrm{OPh}$ (D) species, respectively. Similarly to the Arndtsen's work, ${ }^{[5]}$ these intermediates could transmetalate to give $\mathrm{Ar}-\mathrm{Ni}(\mathrm{CO})-\mathrm{OPh}$ (C) and $\mathrm{Py}-\mathrm{Ni}-\mathrm{Br}$ (E). Reductive elimination from $\mathbf{C}$ would give ester transferred product 3 . On the other hand, reductive elimination from $\mathrm{E}$ could release bromopyridine $\mathbf{4}$ as co-product. However, we did not detect this species. The reason is totally unclear at this stage, but we speculate that reduction of $\mathbf{E}$ by the action of $\mathrm{Zn}$ powder, or the dimerization of $\mathbf{F}$ by nickel-complexes ${ }^{[12]}$ might be involved as undesired pathways.

\section{Scheme 2. Proposed Mechanism.}

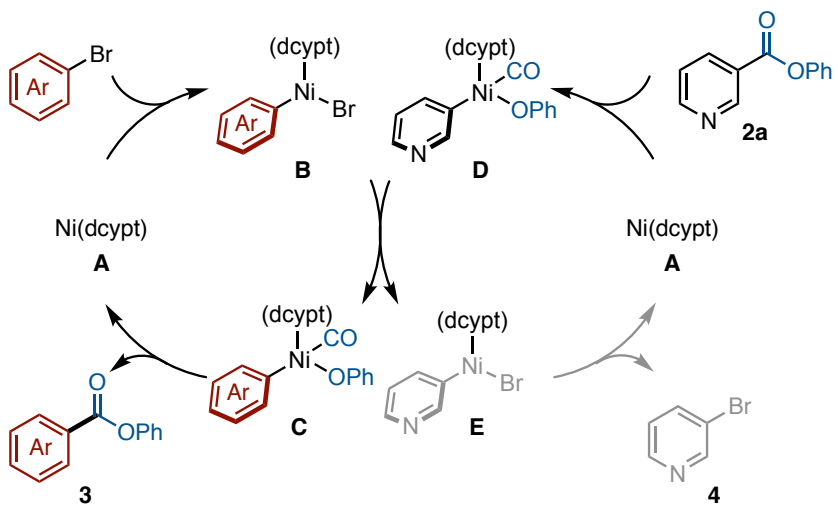

In addition to bromoarenes, chloroarenes were found reactive in the present reaction (Scheme 3A). 2-
Chloronaphthalene (5) participated in this reaction, giving $3 Q$ in acceptable yield ( $50 \%$ yield). Furthermore, the $\mathrm{Ni} / \mathrm{dcypt}$ catalyst is known to oxidatively add into inert $\mathrm{C}-\mathrm{O}$ bonds. ${ }^{[13]}$ Hypothesizing that $\mathrm{C}-\mathrm{O}$-based aryl electrophiles can participate in the present system, we subjected several CO aryl electrophiles with $\boldsymbol{o}$-tolyl ester $\mathbf{2 b}$ (Scheme 3B). ${ }^{[14]}$ Although the yields were moderate, we found that pivalates and carbamates underwent the ester transfer reaction under slightly modified conditions. With the success utilizing aryl pivalates in the present system, we wondered that direct esterification of $\mathrm{Ar}-\mathrm{OH}$ would be possible. As expected, simple arenol 8 could be transformed to aromatic esters 3R in 44\% yield (Scheme $3 \mathrm{C}$ ). In this case, $\mathbf{2 b}$ occupies dual roles; one is an ester source, and the other is an activator of the $\mathrm{Ar}-\mathrm{OH}$ group via the in-situ formation of ester 9 . Subsequent oxidative addition of 9 ( $\mathrm{C}($ aryl $)-\mathrm{O})$ to $\mathrm{Ni} / \mathrm{dcypt}$, followed by transmetalation between $\mathbf{1 0}$ and $\mathbf{1 1}$ produced 3R. In this arenol-based reaction, we did not obtain the corresponding 3hydroxypyridine derivatives at all.

Scheme 3. Ester Transfer using Aryl Chlorides and Arenols. 


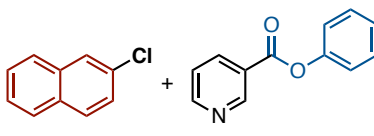

5

2a ( 1.5 equiv)

$10 \mathrm{~mol} \% \mathrm{Ni}(\mathrm{OAc})_{2}$

$20 \mathrm{~mol} \%$ dcypt

$60 \mathrm{~mol} \% \mathrm{Zn}$

$\mathrm{Na}_{2} \mathrm{CO}_{3}$ (1.5 equiv)

$150^{\circ} \mathrm{C}, 12 \mathrm{~h}$

B. Aryl Pivalates and Carbamates

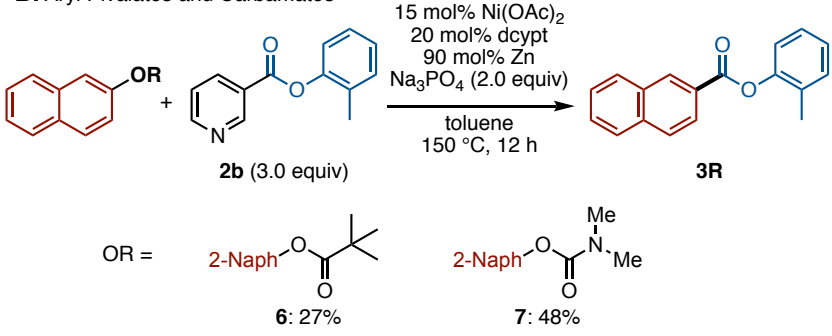

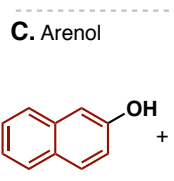

8

2b $\downarrow$

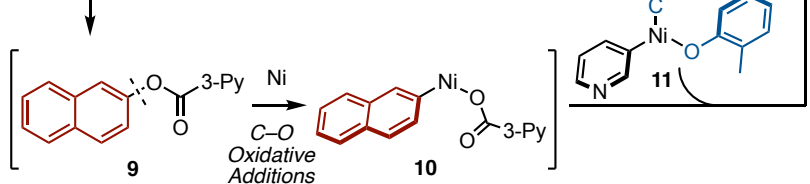

In summary, we have developed a Ni-catalyzed ester transfer reaction between aryl halides and aromatic esters. As an alternative to aryl halides, we successfully utilized phenol-based aryl electrophiles to give ester-transferred product as well. Although the yield and scope of the method have room for improvement, the present result, particularly the utilization of $\mathrm{Ar}-\mathrm{OH}$ as a starting material, could find use in synthetic chemistry as a way of creating valuable products from inexpensive feedstocks. Further studies focusing on the development of other ester transfer reactions and elucidation of the mechanism are underway in our laboratory.

\section{ASSOCIATED CONTENT}

The Supporting Information is available free of charge on the ACS Publications website.

Experimental procedures and spectroscopic data for compounds including ${ }^{1} \mathrm{H}-,{ }^{13} \mathrm{C}$ NMR spectra (PDF)

\section{AUTHOR INFORMATION}

\section{Corresponding Author}

*junyamaguchi@waseda.jp

ORCID

Kei Muto: 0000-0001-8301-4384

Junichiro Yamaguchi: 0000-0002-3896-5882

\section{Notes}

No competing financial interests have been declared.

\section{ACKNOWLEDGMENT}

This work was supported by JSPS KAKENHI Grant Number JP 18H04272, JP19H02726 (to J.Y.), JP18H04661, and JP19K15573 (to K.M.). The Materials Characterization Central Laboratory in Waseda University is acknowledged for the support of HRMS measurement.

\section{REFERENCES}

(1) For reviews on Buchwald-Hartwig aminations, see: (a) Ruiz-Castillo, P.; Buchwald, S. L. Applications of Palladium-Catalyzed C-N Cross-Coupling Reactions. Chem. Rev. 2016, 116, 12564-12649. (b) Dorel, R.; Grugel, C. P.; Haydl, A. M. The Buchwald-Hartwig Amination After 25 Years. Angew. Chem., Int. Ed. 2019, 58, 17118-17129. For similar reviews on Ullmann Condensations, see: (c) Sambiagio, C.; Marsden, S. P.; Blacker, A. J.; McGowan, P. C. Copper Catalysed Ullmann Type Chemistry: from Mechanistic Aspects to Modern Development. Chem. Soc. Rev. 2014, 43, $3525-3550$.

(2) Catalytic carbonylative reactions, see: (a) Brennführer, A.; Neumann, H.; Beller, M. Palladium-Catalyzed Carbonylation Reactions of Aryl Halides and Related Compounds. Angew. Chem., Int. Ed. 2009, 48, 4114-4133.

(3) For reviews, see: (a) Morimoto, T.; Kakiuchi, K. Evolution of Carbonylation Catalysis: No Need for Carbon Monoxide. Angew. Chem., Int. Ed. 2004, 43, 5580-5588. (b) Konishi, H.; Manabe, K. Formic Acid Derivatives as Practical Carbon Monoxide Surrogates for Metal-Catalyzed Carbonylation Reactions. Synlett 2014, 25, 1971-1986. For selected examples, see: (c) Ueda, T.; Konishi, H.; Manabe, K. Palladium-Catalyzed Carbonylation of Aryl, Alkenyl, and Allyl Halides with Phenyl Formate. Org. Lett. 2012, 14, 3100-3103. (d) Park, H.-S.; Kim, D.-S.; Jun, C.-H. Palladium-Catalyzed Carbonylative Esterification of Primary Alcohols with Aryl Chlorides through Dehydroxymethylative C-C Bond Cleavage. ACS Catal. 2015, 5, 397-401.

(4) For a Review on functional group transfers, see: (a) Bhawal, B. N.; Morandi, B. Catalytic Isofunctional Reactions-Expanding the Repertoire of Shuttle and Metathesis Reactions. Angew. Chem., Int. Ed. 2019, 58, 10074-10103. For selected examples, see: (b) Jun, C.-H.; Lee, H. Catalytic Carbon-Carbon Bond Activation of Unstrained Ketone by Soluble Transition-Metal Complex. J. Am. Chem. Soc. 1999, 121, 880-881. (c) Murphy, S. K.; Park, J. W.; Cruz, F. A.; Dong, V. M. Rh-Catalyzed C-C Bond Cleavage by Transfer Hydroformylation. Science 2015, 347, 56-60. (d) Fang, X.; Yu, P.; Morandi, B. Catalytic Reversible Alkene-Nitrile Interconversion Through Controllable Transfer Hydrocyanation. Science 2016, 351, 832 836. (e) Lian, Z.; Bhawal, B. N.; Yu, P.; Morandi, B. Palladium-Catalyzed Carbon-Sulfur or Carbon-Phosphorus Bond Metathesis by Reversible Arylation. Science 2017, 356, 1059-1063. (f) Fan, C.; Lv, X.-Y.; Xie, J.-H.; Zhou, Q.-L. Alkenyl Exchange of Allylamines via Nickel(0)-Catalyzed C-C Bond Cleavage. J. Am. Chem. Soc. 2019, 141, 2889-2893. (g) Kanda, T.; Naraoka, A.; Naka, H. Catalytic Transfer Hydration of Cyanohydrins to $\alpha$-Hydroxyamides. J. Am. Chem. Soc. 2019, 141, 825- 830.

(5) (a) Lee, Y. H.; Morandi, B. Metathesis-Active Ligands Enable a Catalytic Functional Group Metathesis Between Aroyl Chlorides and Aryl Iodides. Nat. Chem. 2018, 10, 1016-1022. (b) De La Higuera Macias, M.; Arndtsen, B. A. Functional Group Transposition: A Palladium-Catalyzed Metathesis of Ar-X $\sigma$-Bonds and Acid Chloride Synthesis. J. Am. Chem. Soc. 2018, 140, 10140-10144.

(6) For reviews on decarbonylative reaction of aromatic esters, see: (a) Takise, R.; Muto, K.; Yamaguchi, J. Cross-coupling of aromatic esters and amides. Chem. Soc. Rev. 2017, 46, 5864-5888. (b) Guo, L.; Rueping, M. Decarbonylative Cross-Couplings: Nickel Catalyzed Functional Group Interconversion Strategies for the Construction of Complex Organic Molecules. Acc. Chem. Res. 2018, 51, 1185-1195. For amides, see: (c) Meng, G.; Szostak, M.; N-Acyl-Glutarimides: Privileged Scaffolds in Amide N-C Bond Cross-Coupling. Eur. J. Org. Chem. 2018, 2352-2365.

(7) For selected examples of Pd- and Ni-dcypt catalyzed reaction involving $\mathrm{C}-\mathrm{C}$ bond activations of aromatic esters, see: (a) Okita, T.; Kumazawa, K.; Takise, R.; Muto, K.; Itami, K.; Yamaguchi, J. Palladium-Catalyzed 
Decarbonylative Alkynylation of Aromatic Esters. Chem. Lett. 2017, 46, 218-220. (b) Takise, R.; Isshiki, R.; Muto, K.; Itami, K.; Yamaguchi, J. Decarbonylative Diaryl Ether Synthesis by Pd and Ni Catalysis. J. Am. Chem. Soc. 2017, 139, 3340-3343. (c) Isshiki, R.; Takise, R.; Itami, K.; Muto, K.; Yamaguchi, J. Catalytic $\alpha$-Arylation of Ketones with Heteroaromatic Esters. Synlett 2017, 28, 2599-2603. (d) Isshiki, R.; Muto, K.; Yamaguchi, J. Decarbonylative C-P Bond Formation Using Aromatic Esters and Organophosphorus Compounds. Org. Lett. 2018, 20, 1150-1153. (e) Okita, T.; Muto, K.; Yamaguchi, J. Decarbonylative Methylation of Aromatic Esters by a Nickel Catalyst. Org. Lett. 2018, 20, 3132-3135.

(8) Muto, K.; Hatakeyama, T.; Yamaguchi, J.; Itami, K. C-H Arylation and Alkenylation of Imidazoles by Nickel Catalysis: Solvent Accelerated Imidazole C-H Activation. Chem. Sci. 2015, 6, 6792-6798.

(9) (a) Knappke, C. E. I.; Grupe, S.; Gärtner, D.; Corpet, M.; Gosmini, C.; Jacobi von Wangelin, A. Reductive Cross-Coupling Reactions between Two Electrophiles. Chem. Eur. J. 2014, 20, 6828-6842. (b) Weix, D. J. Methods and Mechanisms for Cross-Electrophile Coupling of Csp ${ }^{2}$ Halides with Alkyl Electrophiles. Acc. Chem. Res. 2015, 48, 1767-1775.

(10) Muto, K.; Yamaguchi, J.; Musaev, D. G.; Itami, K. Decarbonylative Organoboron Cross-Coupling of Esters by Nickel Catalysis. Nat. Commun. 2015, 6, 7508

(11) (a) Xiao, Y.-L.; Min, Q.-Q.; Xu, C.; Wang, R.-W.; Zhang, X. NickelCatalyzed Difluoroalkylation of (Hetero)Arylborons with Unactivated 1Bromo-1,1-difluoroalkanes. Angew. Chem., Int. Ed. 2016, 55, 5837-5841. (b) Zhang, X.; Xia, A.; Chen, H.; Liu, Y. General and Mild Nickel-Catalyzed
Cyanation of Aryl/Heteroaryl Chlorides with $\mathrm{Zn}(\mathrm{CN})_{2}$ : Key Roles of DMAP. Org. Lett. 2017, 19, 2118-2121.

(12) (a) Semmelhack, M. F.; Helquist, P. M.; Jones, L. D. Synthesis with Zerovalent Nickel. Coupling of Aryl Halides with Bis(1,5-cyclooctadiene)nickel(0). J. Am. Chem. Soc. 1971, 93, 5908-5910. (b) Zembayashi, M.; Tamao, K.; Yoshida, J.; Kumada, M. Nickel-Phosphine Complex-Catalyzed Homo Coupling of Aryl Halides in the Presence of Zinc Powder. Tet rahedron Lett. 1977, 47, 4089-4092. (c) Yamamoto, T.; Wakabayashi, S.; Osakada, K. Mechanism of C-C Coupling Reactions of Aromatic Halides, Promoted by $\mathrm{Ni}(\mathrm{COD})$, in the Presence of 2,2'-Bipyridine and $\mathrm{PPh}$, to Give Biaryls. J. Organomet. Chem. 1992, 428, 223-237.

(13) For examples with $\mathrm{Ni} / \mathrm{dcypt}$ for $\mathrm{C}-\mathrm{O}$ bond oxidative additions, see: (a) Takise, R.; Muto, K.; Yamaguchi, J.; Itami, K. Nickel-Catalyzed $\alpha$-Arylation of Ketones with Phenol Derivatives. Angew. Chem., Int. Ed. 2014, 53, 6791-6794. (b) Koch, E.; Takise, R.; Studer, A.; Yamaguchi, J.; Itami, K. NiCatalyzed $\alpha$-Arylation of Esters and Amides with Phenol Derivatives. Chem. Commun. 2015, 51, 855-857. (c) Takise, R.; Itami, K.; Yamaguchi, J. Cyanation of Phenol Derivatives with Aminoacetonitriles by Nickel Catalysis. Org. Lett. 2016, 18, 4428-4431.

(14) When using simple phenyl ester 2a, it was found that $\mathrm{C}$ (aryl)-O and $\mathrm{C}($ acyl $)-\mathrm{O}$ oxidative additions on $\mathbf{2 a}$ were competitive. The $o$-methyl group probably suppressed the undesired $\mathrm{C}($ aryl $)-\mathrm{O}$ oxidative addition by steric hinderance. 
Insert Table of Contents artwork here

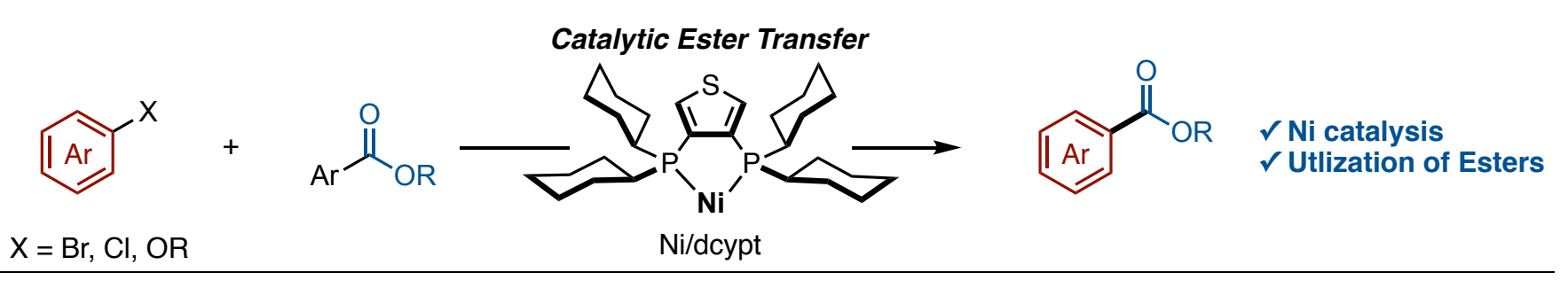

